\title{
A LOOK INTO CIRCULAR ECONOMY RESEARCH: EXPLORING THE BIO AND TECHNO CYCLES AND THE NEED FOR DUAL CIRCULARITY
}

\author{
Metic, Julija; \\ McAloone, Tim C.; \\ Pigosso, Daniela C. A. \\ Technical University of Denmark
}

\begin{abstract}
This study undertakes a systematic analysis of literature within Circular Economy (CE) in an industrial perspective, with a focus on understanding the consideration of the biological and technological cycles, as well as dual circularity. The paper articulates the key research differences, gaps and trends on the basis of publication evolution, key subject areas, influential journals and keywords cooccurrence mapping. The analysis shows the increasing publication trend with dominance of technological cycle and a wide variety of subject areas incorporated in CE biological, technological and dual cycles. Due to the multidisciplinary and transversal nature of $\mathrm{CE}$, as well as its diverse interpretation and applications, an expansion and consolidation of the subject areas and journals are expected in the years to come. Analysis of co-occurrence on the authors' keywords underlined a limited focus of a business perspective research within the biological cycle, heterogeneous and proactive technological cycle but fragmented research on dual circularity. Further analysis of synergies and limitations is necessary to enhance business effectiveness towards enhanced sustainability.
\end{abstract}

Keywords: Circular economy, Sustainability, Innovation, Business models and considerations, Multi/ Cross- / Trans-disciplinary processes

\section{Contact:}

Metic, Julija

Technical University of Denmark

Mechanical Engineering

Denmark

jumet@mek.dtu.dk 


\section{INTRODUCTION}

According to the recent UN report on Sustainable Development Goals the world remains on the path of using natural resources unsustainably. The global population growth and the rising living standards over the last two decades are associated with increasing levels of resource consumption and a growing demand for energy (UN, 2020). European policies are focusing on promoting a transition towards an economy aiming at reducing the dependence from fossil-based resources, limiting environmental impacts, generating social value and ensuring a sustainable economic growth (Corrado and Sala, 2018). Circular Economy (CE) has been widely recognised as promising approach for sustainable development and as an alternative to the current linear take-make-dispose system (EEA, 2020; Stahel, 2016). Because of that, CE has gained great traction in past few years within academia, industry and policy-makers (EEA, 2020). The Ellen MacArthur Foundation describes the CE as an "industrial system that is restorative or regenerative by intention and design" (Ellen MacArthur Foundation, 2013), while European Commission (EC) in the European Action Plan states that CE is a system where the value of products, materials and resources is preserved for as long as possible, and the waste generation minimised (EC, 2015). Although numerous definitions of $\mathrm{CE}$ exist, commonality found between most of them are the "value retention processes" or mechanisms to retain value through reuse, repair, refurbishment, remanufacturing, redistribution and recycling (Blomsma et al., 2019; Nasr et al., 2018; Schöggl et al., 2020).

The CE system diagram by Ellen MacArthur Foundation is the most famous representation model of the CE that distinguished "technosphere" and "biosphere" (The Ellen MacArthur Foundation, 2015a). The adopted notion of separating biological resources, because of their regenerative nature from abiotic or technical materials was put by Michael Braungart and William McDonough in their Cradleto-Cradle philosophy (McDonough and Braungart, 2002). However, in practice, the distinction is not always clear, as many bio-based products actually enter the technical cycle, for example the use of wood and paper in many manufacturing applications (EEA, 2018). Furthermore, organic and inorganic elements are mixed and integrated in resources naturally (sedimentary rocks) or designed in (car components) (Carus and Dammer, 2018; Velenturf et al., 2019).

And while some authors argue that core ideas of CE is to "mimic" biological processes through technological system, most scholars still only focus on cascading and biodegradability of renewable materials in separate cycles (Geissdoerfer et al., 2017; Leipold and Petit-Boix, 2018; Murray et al., 2015). In doing so, they tend to overlook the contribution, such as improving circularity and environmental performance, that renewable feedstock, reuse, refurbishment, remanufacturing and recycling of renewable materials can have (Harris et al., 2018).

It is important to highlight that renewable or bio-based materials are already used in the technical cycle, corresponding to important market opportunities across the economy today and for the future, such as packaging, chemical industry or construction sectors, their deployment drives innovation agenda to build supply chain resilience and support economic growth (Ellen MacArthur Foundation, 2018). Given the influence that the CE concept currently has, there is a clear risk of neglecting the benefits of using and recovering the value of renewable materials at the end of the use, and therefore full potential benefits are not fully attained (Harris et al., 2018). To address this gap, dual circularity approaches refers to the circulation of sustainable biotic industrial and societal product/materials in and between technological and biological loops.

European policy makers have introduced the high-level CE strategy in which business community plays a crucial role by taking up political ideas and applying new business models, and product design practices in moving our societies to CE (Geissdoerfer et al., 2017; Pieroni et al., 2019). Understanding the nature of the technological and biological cycles (dual circularity) when designing and developing solutions that are more circular is, therefore, key for companies to support decision-making for enhanced systemic sustainability performance. Although, sustainability is based on three dimensions, triple bottom line, from holistic perspective: environmental quality, economic prosperity and social equity most of the literature maintains that $\mathrm{CE}$ mainly focuses on environmental aspect, emphasises economic benefit and excludes large parts of social dimension (Geissdoerfer et al., 2017; Jarre et al., 2020).

Further effort is needed to articulate the nuances of the CE to encourage a more comprehensive understanding of the concept (Ellen MacArthur Foundation, 2018). For this reason, it is of high interest to understand the evolution of the studies related to the biological and technological cycles associated to the $\mathrm{CE}$ as well as the industry and business engagement. In this context, this article aims to identify main trends in research related to business and industry engagement in CE considering biological and 
technological initiatives; by identifying the evolution over time, key subject areas, key journals, keywords and topics related to the concepts most contributing to the trends. It intends to present possible trends and gaps for the future initiatives within business and industry engagement regarding CE.

\section{METHODOLOGY}

The goal of this study is to understand the differences of the CE biological and technological research, as well as dual circularity, through a systematic analysis of literature. The review followed four main steps: (1) definition of the search strings - incl. keywords and their synonyms; (2) search of the strings in the Elsevier's Scopus database, with focus on abstract, title and keywords; (3) analysis and discussion of results; (4) conclusion (Figure 1).

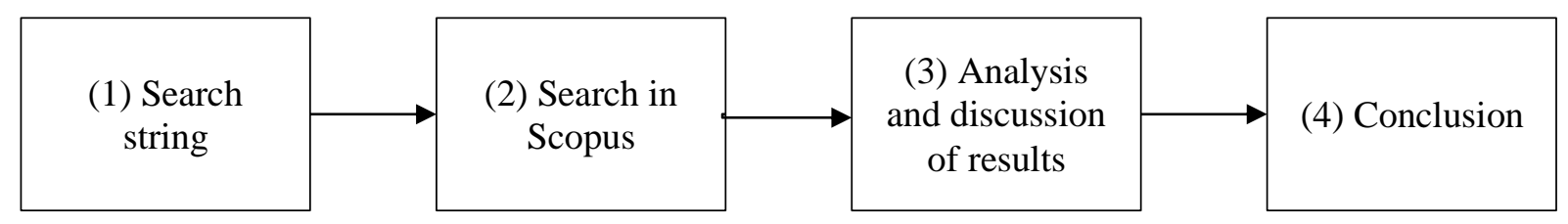

Figure 1. Stages of the analysis

Selection of search criteria was set on all types of documents over all periods, but focused on title, abstract and keywords. Further, study distinguishes literature body on biological and technological research within $\mathrm{CE}$ and the combination of both (dual circularity). Additionally, selected possible synonyms with truncation technique were considered when searching the database, which broadens the search by including various word endings and spelling. Truncation symbols vary by database, in Scopus case that is $\left(^{*}\right)$. For the biological cycle, the considered keywords/synonyms are: (bio* cycle*), (biocycle*), (bio*), (renew*), (organic*) excluding technological keywords. For technological cycle, correspondingly: (techn* cycle*), (techno-cycle*), (techn*), (abiotic*), (non-renew*), (inorganic*) and excluding biological keywords. As third aspect, the combination of both types of keywords was used. Further, to narrow the selection to focus of research, keywords as circular economy (circula* econom*), sustainability (sustain*), businesses (business*), company (compan*), industry (industr*), product (product*) and material (material*) were included. However, the data collection is still limited due to the fact that circular economy as well as product, material, companies and industry have various synonyms and associated concepts, such as industrial ecology, green economy, bio/bio-based/knowledge-based economy, firms, corporations, manufacturing, commerce, goods etc. Nevertheless, in this study we used the main concepts and keywords found across background literature.

- Search string for the bio query: TITLE-ABS-KEY(("“bio*cycle*”) OR ("bio-cycle*”) OR ("bio*") OR ("renew") OR ("organic*”) AND ("circula* econom*”) AND ("sustain*”) AND ("business*”) OR ("compan*”) OR ("industr*”) AND ("product*”) OR ("material*”)) AND NOT (("techn* cycle*”) OR ("techno-cycle*”) OR ("techn*”) OR ("abiotic* cycle*”) OR ("abiotic*”) OR ("nonrenew*") OR ("inorganic*"))) total of 259 results was shown.

- Search string for the techno query: TITLE-ABS-KEY(("techn* cycle*”) OR ("techno-cycle*”) OR ("techn*”) OR ("abiotic* cycle*”) OR ("abiotic*”) OR ("non-renew*”) OR ("inorganic*”) AND ("circula* econom*”) AND ("sustain*”) AND ("business*”) OR ("compan*") OR ("industr*”) AND ("product*”) OR ("material*”)) AND NOT (("bio* cycle*”) OR ("bio-cycle*”) OR ("bio*”) OR ("renew") OR ("organic*"))) total of 529 documents was shown.

- Search string for the bio and techno query: TITLE-ABS-KEY (("bio*cycle*”) OR ("bio-cycle*") OR ("bio*”) OR ("renew*”) OR ("organic*”) AND ("techn* cycle*”) OR ("techno-cycle*”) OR ("techn*”) OR ("abiotic* cycle*”) OR ("abiotic*”) OR ("non-renew*”) OR ("inorganic*”) AND ("circula* econom*") AND ("sustain*”) AND ("business*”) OR ("compan*”) OR ("industr*”) AND ("product*") OR ("material*”)) showed total of 343 results.

The search string was then entered to Scopus in December 2020. Despite the limitations using a single database, Scopus provided enough information for the purpose of this research. Scopus is well curated abstract and citation database (Elsevier Ltd, 2020). This database was considered to be the best option due to its quality, sophisticated tools to search using several bibliographic parameters and analytics, database generation of precise citation results, detailed researchers profiles and insights (Ibid). For the publications identified according to the criteria described, the following criteria were considered for 
the analysis and discussion: number of annual publications, key subject areas, key sources, keywords and journals related to the concepts. Geographical distribution, languages, affiliations and types of published documents were not deliberated. Once the final criteria was set, filtered and collected data, the results were exported with all available information to Microsoft Excel Worksheet in ".xls" or ".csv" format which was used later for the bibliometric analysis and visualisation.

\section{ANALYSIS AND DISCUSSION OF RESULTS}

$\mathrm{CE}$ is an emergent and unambiguous concept. In this research, our focus has been on publications that are connected to the industrial application of CE (i.e. within businesses, companies and industry). The main focus was on the analysis of publications per year, key subjects/areas of knowledge, keywords and most influential journals. Results are further differentiated between biological and technological cycles, as well as combination of both (i.e. dual circularity).

\subsection{Evolution of the number of publications per year}

The historical development of the published articles containing the terms made in string queries are shown in Figure 2.

a) Biological cycle: the first papers related to the keywords of the biological cycle are mentioned in 2005, in the Proceedings: EcoDesign 2005 Fourth International Symposium on Environmentally Conscious Design and Inverse Manufacturing. The field is marked by stagnation and negligible number of published papers from 2005 until 2012. Up to 2014 altogether 7 papers were published. Afterwards, 5 papers were published just in 2015, followed by 8 in 2016. Already in 2017, the number of published papers shows a growth, but this time much more intense with 18 papers in 2017, 37 in 2018, 73 in 2019 and 106 in 2020. The results shows an emerging trend and importance of the topic in the literature body.

b) Technological cycle: first article was also published in 2005; a slightly higher number of articles and moderate growth can be observed from 2006 until 2014. As of 2015 (10 publications), there is a significant jump in published papers per year: 25 in 2016, 58 in 2017, 84 in 2018, to 146 in 2019, and 162 in 2020 respectively. It might be connected to the higher attention to the aspect of technological side of the CE in academia and industry. c) Dual circularity: it was first recorded in 2008, but the topic did not show explicit attention before 2014/2015, with 6 and 8 publications, respectively. As noticeable in Figure 2, from 14 publications in 2016, more than 50\% was published in the subsequent year (36). Moving forward, 2018 had 59 publications, 201992 and 2020111 respectively. It shows as well the growing importance of this topic in the literature.

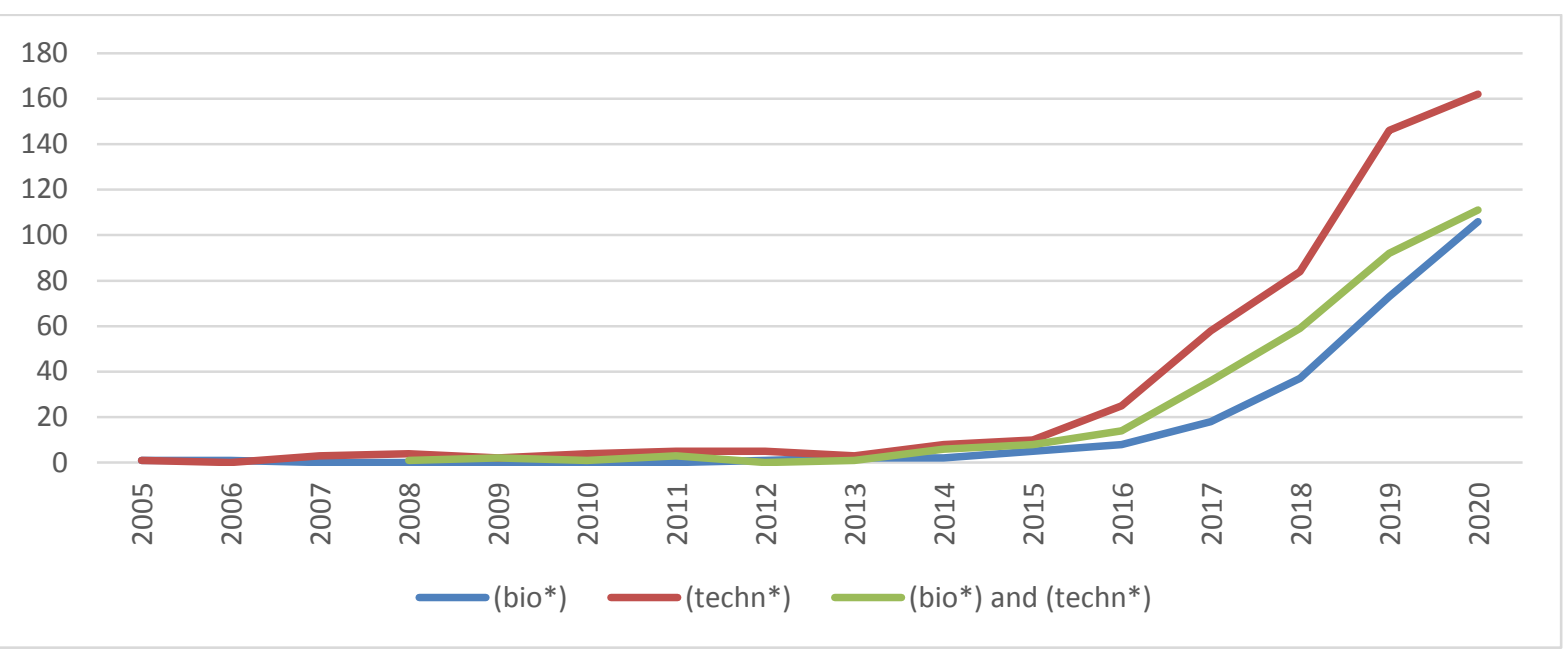

Figure 2. Annual evolution of publications

Within the industrial application of the CE, it can be noted the dominance of the technological cycle in detriment to the biological cycle, with a highest number of studies and a faster development in the recent years. Considering the prevalence of technological cycle and undermining the biological cycle, the need to understand complementary of including dual circularity within CE for businesses and industry perspective is still high. 


\subsection{Key subject areas}

Given the versatility of $\mathrm{CE}$, this research sought to understand in what topics of knowledge the publications related to $\mathrm{CE}$, biological and technological cycles within business, companies and industry have been published, and which of them are becoming an emerging source for the academy.

As seen from the Figure 3,15 key subject areas were identified. There is a wide variety of areas of knowledge dealing with the explored subjects, and evidently, several of the articles analysed match to more than one area of knowledge. The most prominent subject area is Environmental Science (590 publications), the second is Energy (408 publications) followed by Engineering (312 publications) and Business, Management and Consulting (212 publications). Environmental Science being the most dominant subject area is not surprising due to increasing environmental awareness with both policy makers and consumers which see the CE as possible strategy that can promote clean growth and improve environmental conditions. In addition to that, several fields could be noted as emergent subject areas - Social Sciences (162 publications) - demonstration the importance of the social dimension for CE; Chemical Engineering (122 publications); Agriculture and Biological Science (106 publications); Economics, Econometrics and Finances (97 publications); and Material Science (93 publications). In the subject areas of Environmental Science; Energy; Engineering, Business, Management and Accounting, the biological cycle and dual circularity strings seem to be similarly represented while the technological cycle is dominant. Logically, dual circularity and biological cycle are more dominant in the Chemical Engineering; Agricultural and Biological Science; Biochemistry, Genetics and Molecular Biology subject areas. In most of the mentioned emerging areas, the technological topics are leading, with a higher number of documents published. It is interesting to note one possible emerging trend, where the technological cycle is pioneering new subject areas (e.g. Economics, Econometrics and Finance; Computer Science; Earth and Planetary Sciences, Physics and Astronomy, and Decision Sciences), being subsequently followed by dual circularity research.

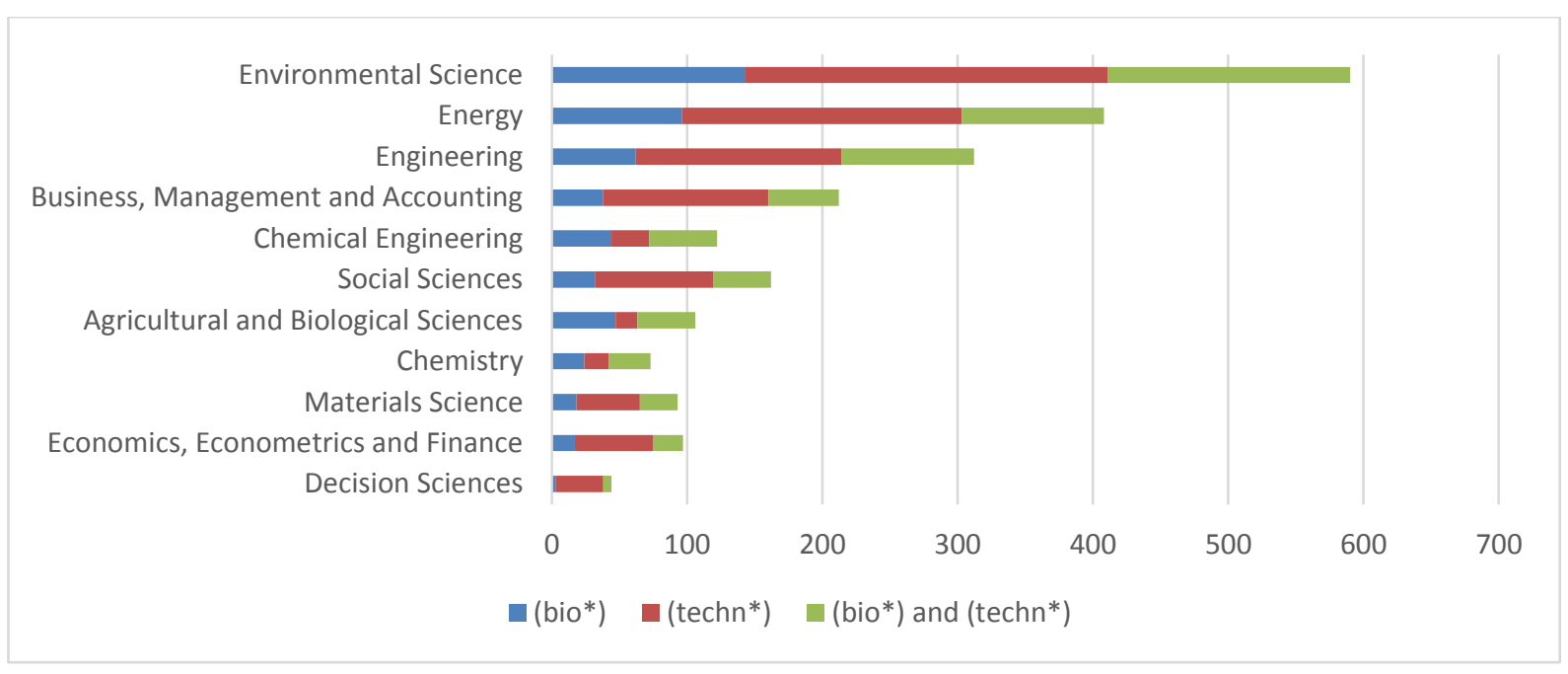

Figure 3. Number of articles published per subject areas

\subsection{Most influential journals}

Publication related to the mentioned topics can be found in a wide range of knowledge areas and therefore in different journals. There are more than 100 journals that have published articles on these topics, which indicates their importance in the academy, especially in the recent years.

The 10 most influential journals are represented, Figure 4. Corresponding to the subject area of Environmental Science, the Journal of Cleaner Production is the leader with the largest number of publications (122). The following most represented journals are Sustainability Switzerland (63 publications) and Resource Conservation and Recycling (48 publications). It is possible to conclude per number of publications per year that the technical segment has the dominance in the selected journals, especially in the Journal of Cleaner Production, the Procedia CIRP and the Journal of Industrial Ecology. Dual circularity segment was interestingly found central in Science of the Total Environment. 


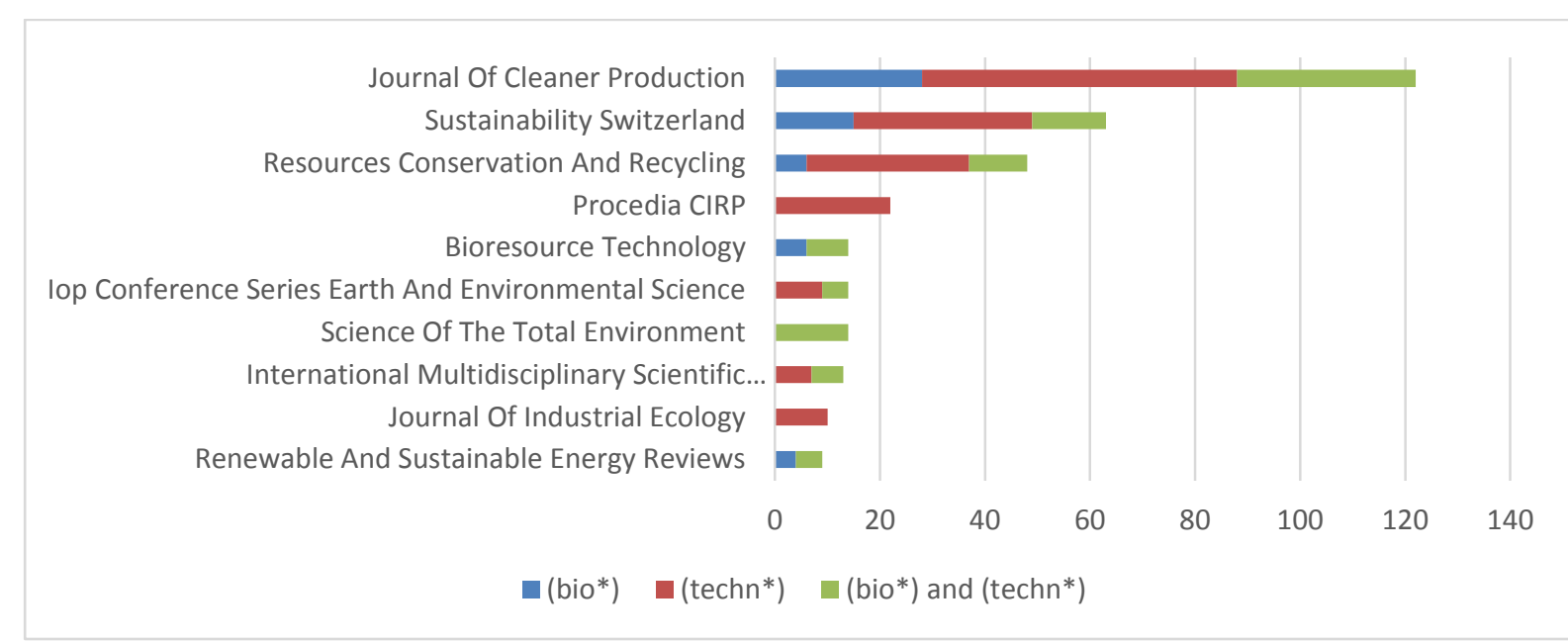

Figure 4. Most influential journals

Looking from a holistic point of view, only three journals present a combination of the three fields (i.e. Journal of Cleaner Production, Sustainability Switzerland, and Resources, Conservation and Recycling. In total, 4 journals focus only in two of the fields (i.e. Bioresource Technology and Renewable and Sustainable Energy reviews - with focus on the bio cycle and dual circularity; and Iop Conference Series Earth and Environmental Science, and International Multidisciplinary Scientific Research - with focus on the technological cycle and dual circularity). Finally, three journals present only one of the three fields (i.e. Science of the Total Environmental, with sole focus on dual circularity; and Procedia CIRP and Journal of Industrial Ecology, with the sole focus on the technological cycle).

\subsection{Most used authors keywords}

Figure 5Figure 5 shows a map based on bibliographic data on co-occurrence on the authors keywords using a full counting method in VosViewer software version 1.6.16. Data was incorporated from the Scopus bibliographic database. The minimum of occurrence of a keyword was established as 5 . Out of the 881 keywords, 21 met the threshold for the bio cycle. Out of the 1581 keywords, 41 meet the threshold for techno cycle, and out of the 1179 keywords, 29 met the threshold for dual circularity data. For each of the keywords, the total strength of the co-occurrence links with the other keywords were calculated. The keywords with the grates total link strength were selected.

The maps in Figure 5, represent A) data on bio cycle, B) data on techno cycle and C) data on dual circularity, correspondingly. The maps are useful to see the trends on the research related to the selected topics. Not unexpectedly, commonalities that can be noted between all three maps are circular economy and sustainability as central figures of research - which demonstrates the role of Circular Economy as a means towards sustainability. Additionally, the maps also show the main interactions between the most frequent keywords in the research, and the existing clusters reflecting the connected topics highlighted in different colours. The keywords representing the greater frequency are represented with bigger circles while the lines represent the closeness of connections between the keywords, the ticker the line between two words, the closer the relationship.

In the bio cycle, there are 5 clusters, the first one in green encompasses most of the keywords including: circular economy, sustainability, recycling and waste as most important terms. Which indicated that this cluster of keywords absorbs more attention from researchers and it is represented as more centralized field. Second in red refers to biomass, bioenergy and bio refinery. Third in blue to anaerobic digestion and biogas with industrial symbiosis; fourth cluster contains bio economy, biotechnology and innovation, and in fifth is only bioplastic. On the basis of the clusters and their centrality, it can be argued that the research within the bio cycle is still mostly focusing on the recirculation of materials within the circular systems, though materials and/or nutrients/energy recovery.

In the techno cycle, there are 9 clusters, which represent a higher diversity of keyword areas in comparison to the bio cycle. The first cluster absorbing the most attention in red relates to the circular business models, industry 4.0, literature review, supply chain management and sustainable production. In addition to being able to present the connection among different business processes (i.e. business model innovation, supply chain and manufacturing) with digitalisation as an enabler for CE, it is interesting to see literature review as an important keyword, as it highlights the type of research that is currently taking 
place within this field, especially after the extreme development of the field in the recent years, highlighted in Figure 3. Second following in green contains keywords as climate change, waste, cleaner production and resource efficiency. This cluster seems to be more focused on traditional approaches for sustainability management in industry, with a focus on reactive approaches (i.e. waste management and cleaner production) and climate change. Third cluster in blue encompasses sustainable development, industrial ecology and industrial symbiosis as main terms. It can be argued the strong roots of this cluster within the traditional industrial ecology foundation for CE. Forth (yellow) terms are circular economy, barriers, plastics and again circular business models. It is an emerging field, given the importance of the plastic waste within a European context, as highlighted by the Ellen MacArthur Foundation and the European Commission. In fifth (purple) those are e-waste, sharing economy, reverse logistics and WEEE. The cluster is grounded in the Electric and Electronic Equipment (EEE) industry, and clearly shows a transition to a sharing economy, where reverse logistics is an integral part of the value chain. In sixth (turquoise) we find term recycling dominating, reuse and eco-design. It is interesting to see ecodesign connected mostly with recycling and reuse, especially when considering the very strong importance of design in defining the overall circularity of products and technologies. Seventh (orange) contains terms as case study, business models and business models innovation - mostly focused on systemic solutions towards CE implementation in industry - targeted at changing the logic of industry in creating, capturing and delivering value. The 8th cluster (brown) refers to the aspect of sustainability and product service systems (PSS) with digitalization and ninth (pink) encompasses life cycle assessment (LCA), waste management and resource recovery. It is also interesting to note the relatively small role that LCA is playing within a CE context.

Similarly to the bio cycle, the dual circularity figure also has 5 clusters. The most prominent ones gaining the most attention are cluster one (green) referring to circular economy, sustainability, sustainable development, waste management, climate change, cleaner production and renewable energy and two (red) referring to recycling, waste, industrial ecology, bio refinery, by-products etc. It is interesting to note that the two most prominent clusters seem to be connected to the technological cycle (cluster 1) and the biological cycle (cluster 2) - which still demonstrates a fragmentation within the field. Third cluster in blue encompasses bioenergy, resource recovery, anaerobic digestion, bioactive compound and microalgae. Fourth (yellow) refers to terms as life cycle assessment, resource efficiency and food waste while for fifth (purple) those are bio economy, biomass and technoeconomic analysis. It can be argued that cluster 5 is the one with the highest integration between the bio- and techno-cycles, or the one with the strongest dual circularity focus.

Based on the analysis, certain trends and gaps can be recognized regarding these three segments. CE is impregnating the management of companies and industry in very diverse activities and productive sectors. For example, bio cycle seems to lack the business perspective as well as climate change aspect while the emphasis is on traditional bio-based materials and energy. If limited importance is attributed to the circularity more holistically, there is at risk of becoming a 'business as usual' scenario. In techno cycle, the attention is mostly on the business perspective, industry, business models and management, while sustainable consumption, climate change, reverse logistics, PSS, sharing economy, eco-design, barriers etc. can be noted as emergent research lines. Similarly to the bio cycle, the dual circularity segment seem to focus mostly on waste management and recycling (which entails a more reactive approach to $\mathrm{CE}$ ), but there are several emergent terms important to notice: climate change, bioactive compounds, microalgae and techno-economic analysis. It is interesting to see sustainability following the concept of CE, and it would be interesting to understand how all three dimensions: environmental, social and economic comprising sustainability connect and correlate to other terms in the each segment.

\subsection{Discussion}

Even though origins of CE date back to the 1970s and 1980s, the concept have been popularized after 2000s (Geissdoerfer et al., 2017). Results on the biological, technological and dual circularity within $\mathrm{CE}$ from business perspective shows that the popularity of the mentioned topics in research has increased consistently after 2014, probably fuelled by national, European and global policy development in CE. Documents on technological aspects have been mostly published, regarding it as most widespread research segment with various contributions from business standpoint which highlights its implications in real-world application with focus on environmental care. 
A)

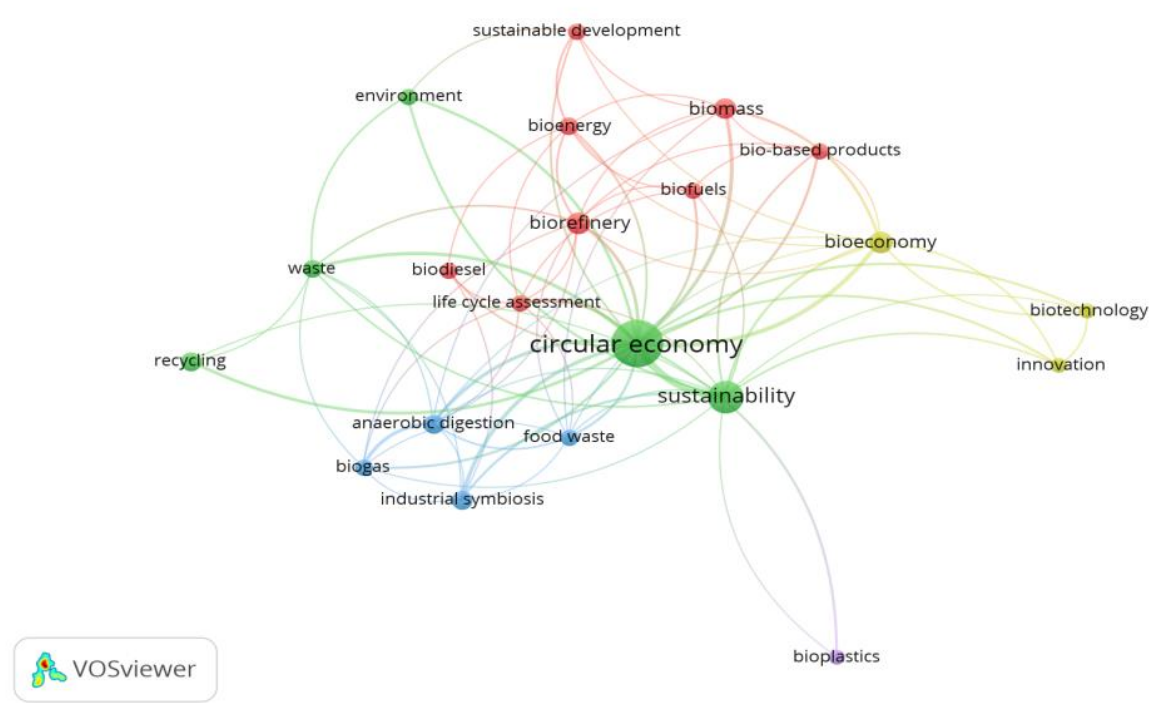

B)

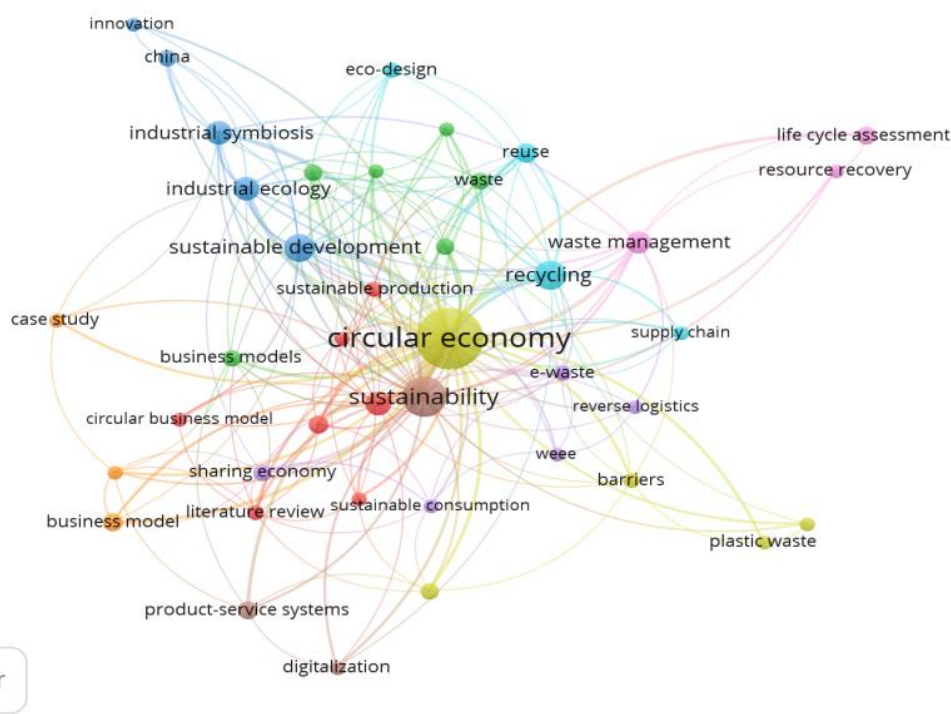

C)

f
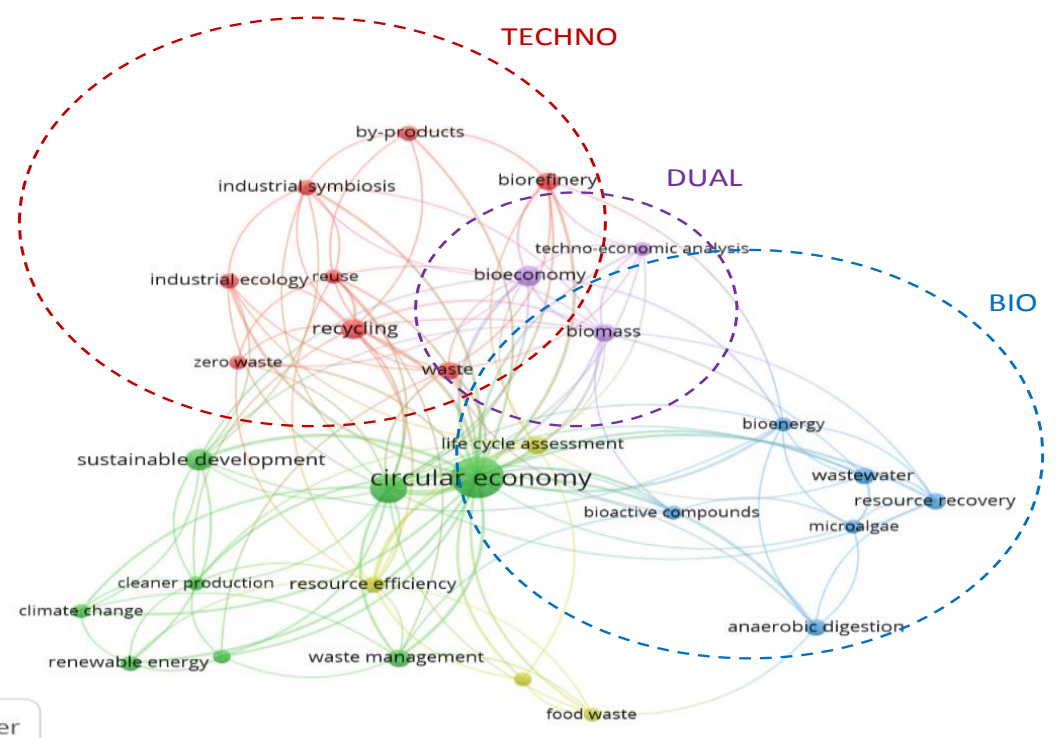

\& VOSviewer

Figure 5. Maps based on co-occurrence on the authors keywords $A$ ) bio cycle $B$ ) techno cycle and C) dual circularity 
Consequentially, bio cycle is lacking this aspect in research by focusing on areas as agriculture and biological science. Dual circularity as well does not seem to contribute to the same extent. The analysis of keyword terms occurrence reveals that literature on technological segment is more diverse and proactive, harbouring a certain internal variety regarding research lines and content, while bio and dual circularity can be noted as more homogeneous and reactive, not yet fully exploring the potential for business and enhanced sustainability for businesses. Incorporating both cycles in dual circularity initiatives could potentially help companies in fully capturing the value creation decoupled from resource consumption, which can be boosted by analysing and managing potential trade-offs and rebound effects when incorporating new circular initiatives. In the long run this represent an opportunity and ambition to transition businesses to more sustainable path.

\section{CONCLUSION}

This research was aimed to perform systematic analysis of literature complemented with a bibliometric analysis with a goal to understand the differences of the research within CE biological and technological cycles as well as dual circularity.

Despite their evidently different aspects, the biological and technological cycles of CE are joint by the common ideal to reconcile economic, environmental and social dimension of businesses. In the past several years, they have gained academic, industrial and politic interest. This comparison of all three areas (bio cycle, techno cycle and dual circularity) within CE provides important information of gaps and trends in current research and body of literature.

The research showed that three segments have experienced growth in research with dominance of technological aspect. It is not surprising due to policy influences all over the world on sustainable economic transition. Biological and dual circularity did not experienced as intensive growth in publications as technological but it can still be regarded as significant. There is a clear evidence of current importance of these topics.

Along with the development of CE, there are a wide variety of subject areas within the bio-, technocycle and dual circularity. Due to the multidisciplinary and transversal nature of the concept as well as diverse interpretations and application of the $\mathrm{CE}$, an expansion and consolidation of the subject areas and journals are expected in the years to come. It is especially interesting to note the emergence of specialised journals, solely focused on CE, such as the "Circular Economy and Sustainability" journal. By using bibliographic data on co-occurrence on the authors' keywords, it was possible to identify gaps and trends between different segments of CE. Key gaps within the bio cycle research are related to the limited focus on the business perspective. Techno aspect is noted as more heterogeneous with the attention to business perspective and industry system while sustainable consumption, climate change, reverse logistics, PSS, sharing economy, barriers etc. can be noted as emergent research lines. Similarly to the bio cycle, dual circularity focuses on waste management and recycling, and it would be interesting to move towards a more proactive approach, with a full integration of the bio- and techno-cycles. Furthermore, further analysis of synergies and limits among dual circularity are necessary to enhance the business effectiveness of implementations towards common sustainability goals.

The work is not exemption to the certain limitations, some of which could be the basis for future research. Limitations can be derived directly from the characteristic of bibliometric analysis, which is the method of quantitative analysis by nature. Further, as mentioned in methodology certain keywords as have various synonyms and associated concepts which are not being used in this research and probably can disregard certain results. Furthermore, due to multiple and diverse definitions of circular economy, intrinsic differences may exist in how the concept is treated and connected to certain areas of knowledge, keywords and journals. Finally, the choice of single database due to inability of VOSviewer to use bibliographic data from more than one database, can be limiting factor for number of publications indexed in other databases. Therefore, the search should be expanded in the future to other databases such as Web of Science (WOS). It would also be a benefit to look into grey literature, to understand the trends from an applied point of view.

\section{ACKNOWLEDGMENTS}

We would like to acknowledge the support provided by the EuroTech Universities Alliance Initiative to enable the realisation of this research. 


\section{REFERENCES}

Blomsma, F., Pieroni, M., Kravchenko, M., Pigosso, D.C.A., Hildenbrand, J., Kristinsdottir, A.R., Kristoffersen, E., et al. (2019), "Developing a circular strategies framework for manufacturing companies to support circular economy-oriented innovation", Journal of Cleaner Production, Elsevier Ltd, Vol. 241, available at: https://doi.org/10.1016/j.jclepro.2019.118271.

Carus, M. and Dammer, L. (2018), "The Circular Bioeconomy - Concepts, Opportunities, and Limitations”, Industrial Biotechnology, available at: https://doi.org/10.1089/ind.2018.29121.mca.

Corrado, S. and Sala, S. (2018), "Bio-Economy Contribution to Circular Economy", available at: https://doi.org/ 10.1007/978-3-319-66981-6_6.

EC. (2015), Closing the Loop - An EU Action Plan for the Circular Economy, Brussels.

EEA. (2018), The Circular Economy and the Bioeconomy - Partners in Sustainability, available at: https:// webcache.googleusercontent.com/search?q=cache:kFjGbHJEzjMJ:https://www.eea.europa.eu/publications/cir cular-economy-and-bioeconomy/download+\&cd=1\&hl=en\&ct=clnk\&gl=dk (accessed 12 November 2020).

EEA. (2020), "Paving the way for a circular economy: insights on status and potentials — European Environment Agency", available at: https://www.eea.europa.eu/publications/circular-economy-in-europe-insights (accessed 2 November 2020).

Ellen MacArthur Foundation. (2013), Economic and Business Rationale for an Accelerated Transition, Towards the Circular Economy.

Ellen MacArthur Foundation. (2018), Renewable materials for a low-carbon and circular future CE100 .

Elsevier Ltd. (2020), “About Scopus - Abstract and citation database | Elsevier”, available at: https://www. elsevier.com/solutions/scopus?dgcid=RN_AGCM_Sourced_300005030 (accessed 8 December 2020).

Geissdoerfer, M., Savaget, P., Bocken, N.M.P. and Hultink, E.J. (2017), "The Circular Economy - A new sustainability paradigm?", Journal of Cleaner Production, Elsevier Ltd, 1 February.

Harris, S., Staffas, L., Rydberg, T. and Eriksson, E. (2018), Renewable Materials in the Circular Economy, available at: www.ivl.se (accessed 19 November 2020).

Jarre, M., Petit-Boix, A., Priefer, C., Meyer, R. and Leipold, S. (2020), “Transforming the bio-based sector towards a circular economy - What can we learn from wood cascading?", Forest Policy and Economics, Elsevier B.V., 1 January, available at: https://doi.org/10.1016/j.forpol.2019.01.017.

Leipold, S. and Petit-Boix, A. (2018), "The circular economy and the bio-based sector - Perspectives of European and German stakeholders", Journal of Cleaner Production, Elsevier Ltd, Vol. 201, pp. 1125-1137.

McDonough, W. and Braungart, M. (2002), Cradle to Cradle.

Murray, A., Skene, K. and Haynes, K. (2015), “The Circular Economy: An Interdisciplinary Exploration of the Concept and Application in a Global Context", Journal of Business Ethics, Vol. 140, available at: https://doi.org/10.1007/s10551-015-2693-2.

Nasr, N., Russell, J., Bringezu, S., Hellweg, S., Hilton, B., Kreiss, C. and von Gries, N. (2018), Re-Defining Value - The Manufacturing Revolution. Remanufacturing, Refurbishment, Repair and Direct Reuse in the Circular Economy.

Pieroni, M.P.P., Mcaloone, T.C. and Pigosso, D.C.A. (2019), "Business model innovation for circular economy and sustainability: A review of approaches", available at: https://doi.org/10.1016/j.jclepro.2019.01.036.

Schöggl, J.P., Stumpf, L. and Baumgartner, R.J. (2020), "The narrative of sustainability and circular economy A longitudinal review of two decades of research", Resources, Conservation and Recycling, Elsevier B.V., 1 December, available at: https://doi.org/10.1016/j.resconrec.2020.105073.

Stahel, W.R. (2016), Circular Economy.

The Ellen MacArthur Foundation. (2015a), Growth within: a circular economy vision for a competitive Europe. UN. (2020), The Sustainable Development Goals Report 2020.

Velenturf, A.P.M., Archer, S.A., Gomes, H.I., Christgen, B., Lag-Brotons, A.J. and Purnell, P. (2019), "Circular economy and the matter of integrated resources", Science of the Total Environment, Elsevier B.V., 1 November. 